\title{
Hosting Capacity Analysis: A Review and A New Evaluation Method in Case of Parameters Uncertainty and Multi-Generator
}

\author{
S. Mina Mirbagheri \\ Energy Department \\ Politecnico di Milano \\ Milan, Italy \\ sayedehmina.mirbagheri@polimi.it
}

\author{
Davide Falabretti \\ Energy Department \\ Politecnico di Milano \\ Milan, Italy \\ davide.falabretti@polimi.it
}

\author{
Valentin Ilea \\ Energy Department \\ Politecnico di Milano \\ Milan, Italy \\ valentin.Ilea@polimi.it
}

\author{
Marco Merlo \\ Energy Department \\ Politecnico di Milano \\ Milan, Italy \\ marco.merlo@polimi.it
}

\begin{abstract}
The rapid growth of distributed energy resources exploitation can cause voltage violations and overloading on distribution grids due to the uncontrolled and unprogrammable power injections associated with dispersed generators. To overcome these issues, distributed system operators have to evaluate the maximum generation that can be hosted by distribution grids without violating the technical constraints and find the ways to increase it. In this paper, different hosting capacity analyses for different case studies have been reviewed, and a novel model to evaluate hosting capacity in case of grid parameters uncertainties and multi-generator connection is proposed.
\end{abstract}

\section{INTRODUCTION}

$\mathbf{T}$ he increasing penetration of Dispersed Generation (DG), mainly based on Renewable Energy Sources (RES) on both Low and Medium Voltage (LV-MV) levels, causes complexity and challenges in the modeling and operation of distribution grids. Low greenhouse gas emissions, better sustainability and less maintenance strongly motivate installing DGs. However, the massive DG connection and its uncontrolled and unprogrammable power injections into the grid may cause power quality and reliability issues (e.g. voltage profile and conductors' ampacity problems, harmonics, issues related to unwanted island phenomena, etc.), due to not considering the actual distribution grid power needs, and consequently it may require the introduction of new interventions on the grid devoted to improve the ability of the grid to accept local generation without incurring in technical problems [1]-[5].

Since a proper management of DGs on distribution grids is vital, strong research activities based on statistical, deterministic and heuristic approaches have been done in order to ensure that, with a given amount of DG connected to the distribution grid, the electrical network is still working within the admitted operational ranges imposed by technical standards and regulatory agencies [6], [7]. Although imposed grid regulations do not allow Distributed System Operator (DSO) to refuse any request of DG connection in any location of distribution grid [8], the goal of many research works is determining the optimal DG sizing and siting [9], [10]. However, these studies have a scarce applicability in real-life. In this regard, evaluation of the maximum generation that can be hosted by the distribution grid without violating the technical grid constraints is one of the main performance indicators that should be considered for planning and operation of the grid. This capacity of the electrical network is commonly known as Hosting Capacity ( $H C$ ).

The HC method is based on the fact that power system performance is affected by every change in the generation and the load pattern. Hence, the HC is defined by an algorithm considering the amount of acceptable DG without endangering the grid power quality and reliability with respect to some limits, i.e. steady-state voltage limits, transformer and lines thermal limits and fast voltage variations [1], [11]-[13]. The approaches proposed in the literature are mainly based on iterative calculations, aiming at estimating the maximum DG penetration admitted in every bus according to the considered technical limits; the $\mathrm{HC}$ is evaluated considering a single constraint at each time and assuming the overall $\mathrm{HC}$ as the minimum $\mathrm{HC}$ amount obtained for all the constraints. Hereinafter, such an index will be referred as "Nodal HC (NHC)". Although NHC gives us a right view of the power injection admitted in each node of the grid, it does not provide enough indications about the combined effects that many DG units installed in different nodes of the network would have on its operational parameters, as usually occurs in real life scenarios [14]. Thus, evaluating "Multi Generator HC $(M G H C)$ " is inevitable in distribution grids. This is an upto-date approach and very few works could be found in literature in such a direction.

The aim of this paper is reviewing the literature of different HC evaluation research works, since none of the papers in literature cover all the HC topics, and the ways to increase it. Moreover, it proposes a novel model to evaluate HC in case of grid parameters uncertainties. To do so, a literature overview with a span of one decade from 2007 until 2018 has been carried out using IEEE/IET/Elsevier and thesis databases. The structure of this paper is as follows: section II represents HC methodology, and section 


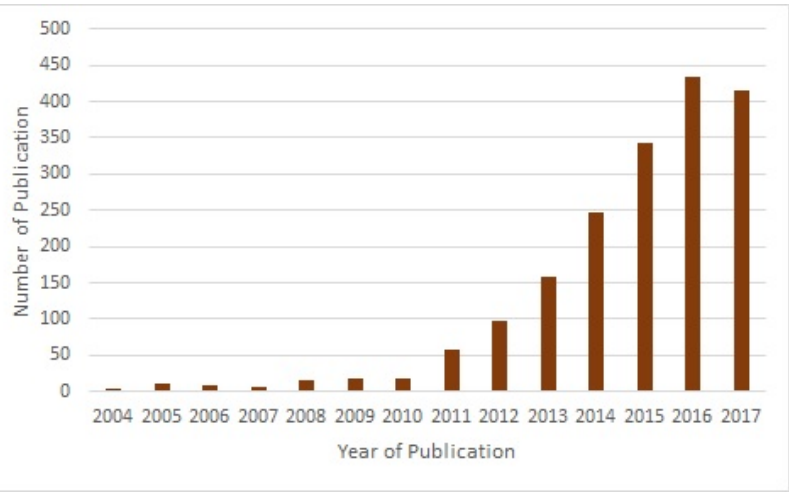

Fig. 1: Number of publication using term "Hosting Capacity".

III is devoted to increasing HC approaches. The proposed approaches and its results have been explained in section IV. At the end, section V concludes this study.

\section{Hosting CAPACity Methodology}

The Hosting Capacity is the amount of new production that can be connected to the grid in a specific location or over a given area without exceeding the technical limits of the network during operation. The HC method was originally discussed as part of EU-DEEP project by STRI in 2004 [1], [15]-[17]. Fig. 1 depicts the number of publications using the exact term of "Hosting Capacity" in the same direction of the research has been performed in each year from 2004 until 2017 according to Google Scholar.

Typically, in literature the $\mathrm{HC}$ approach is presented as shown in Fig. 2 [18]. The amount of HC is defined when the blue curve is going to violate the red dashed line, representing the system limits, as better detailed in the following: 1) choose one or more suitable performance indicators (e.g. voltage or current amplitude); 2) define appropriate limits; 3) compute the performance indicators as a function of generation; 4) obtain HC with the highest amount of generation where none of the performance indicators violate their admitted thresholds [19].

Estimating the NHC for LV Italian grid based on iterative calculations (1 kW step) has been studied in [20]: in this work, the NHC is evaluated considering a single constraint at each time and assuming the overall $\mathrm{HC}$ as the minimum HC amount obtained for all the constraints. This paper concludes that, as expected, the maximum HC is observed near HV/MV substations. Moreover, the rural networks have a limited HC compared to urban networks, due to

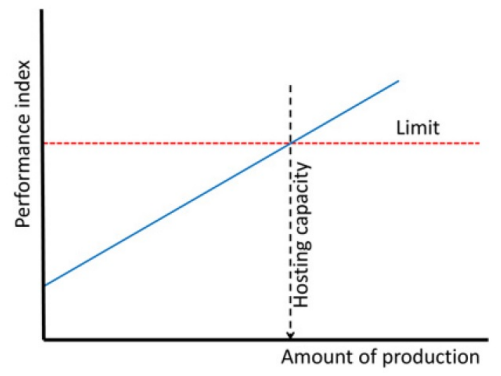

Fig. 2: Basic description of HC. the limited cross sections and long length of their lines. Different softwares for performing Power Flow (PF) have been used by researchers, e.g. a NHC evaluation has been discussed for 73-node and 19-node Jordanian network grid with high $(\mathrm{X} / \mathrm{R})$ ratio in [21] using Newton-raphson in MATPOWER. [22] has discussed NHC performed with software SimPow for a distribution grid at the centre of Sweden. MATPOWER and MADGTPOWER for nonlinear numerical methodes have been used in [23] for NHC estimation. Eventually, Swedish regional distribution grid in [11] used commercially available power system simulation software for assessing NHC.

In order to define the possible injection into the grid by DGs, it is very important to choose suitable performance indicators including directly related (such as upper bound and lower bound of RMS voltage) or indirect ones (such as transformer thermal limits) [19]. Typically, researchers consider the main technical constraints such as Steady State Voltage Variations (SSV), thermal limits and Rapid Voltage Change (RVC) [4], [11], [20]-[27]. In [11], the most limiting factor for the HC are the overcurrents. The authors in [24] mentioned that the factors limiting the HC depend on the type of network and its voltage level. In weak MV networks (i.e. characterized by long lines), the voltage rise is usually the main limiting factor, while in stronger networks (e.g. urban grids) the feeder and transformer overloading is. In [29] author uses an exhaustive method to evaluate the NHC considering voltage levels and conductor's current flows as technical constraints. For each node at each time a defined maximum value of $\mathrm{HC}$ is selected and a PF is performed to check the compliance of voltage and current constraints; in case of violation, HC is reduced via bisection method until a viable value is found. Since the dynamic behavior of background distortion (e.g. harmonics) may change HC, the harmonic distortion phenomenon has been considered as the technical constraint in [30], in order to have a more efficient distributed generation planning.

Solving optimization problems to obtain HC has been considered in some research papers. A novel Optimal Power Flow (OPF) with the objective of maximizing the nodal loading parameters to evaluate NHC and to define the DG control rules has been proposed in [27], [28]. The authors of these papers conclude that the maximum HC is obtained on the location where feeder is most loaded. The more distance from the MV Primary Substation (PS), the less increase of HC, since the nodes at the end of the feeder experience severe problems of undervoltage. The authors in [31] mentioned that the best location for connecting a DG unit is close to the load center and two optimization models using Primal-dual interior-point method to calculate and optimize the voltage profile and line losses have been proposed. The objective functions in [32] are the energy purchased and the operation and maintenance cost of a wind farm; the problem is solved by NSGA-II algorithm. In this paper, the network parameters uncertainty has been considered as input and a two-stage stochastic method has 
been used in order to make decisions under uncertainty.

To consider the stochastic nature of loads, generation and DG location Monte Carlo simulation was used [33]. Probabilistic Load Flow (PLF) may be more adequate compared to Deterministic Load Flow (DLF), because of the realistic representation of the inputs and the probabilistic margins obtained with respect to the technical constraints violation. In [34], probabilistic load modeling and costumer's hourly power request probability have been considered. Then, the probability density function of each technical constraints for DGs has been estimated by Monte Carlo simulation. The Swedish distribution grid in [35] has been divided into rural, residential and city areas; Monte Carlo has been used in this study to assess the probability of the technical constraints at different voltage levels. A LV Slovenian distribution network has been modeled in [36] using statistical Monte Carlo simulation. In this study, the probability of voltage violation with respect to installed PV capacity is evaluated. A probabilistic method has been proposed in [37] for assessing the impact of Low Carbon Technologies (LCTs) in LV networks considering network parameters uncertainty. This work highlights that the Cumulative Density Functions (CDFs) for each feeder could show to DSO the customers with high probability to cause voltage or thermal problems.

The authors of [12] proposed an approach to consider the maximum injection "equivalent" to the generators downstream the bus under examination. This method is useful for considering MGHC where the total injection is equal to the equivalent generator.

\section{Hosting CAPACITY INCREASING}

For planning issues it is a major concern to evaluate the upper limit of total RES injection to the grid and the ways to increase it without reinforcement. In the following, HC increasing approaches are explained.

\section{A. Voltage Control}

Local voltage control by using local information allows to increase HC; it is also called decentralized method. The local voltage control may be performed by the regulatory of on load tap changer (OLTC) in Primary Substation (PS) and the Power Factor Control (PFC) of DG.

The voltage set-point of MV bus-bar at PS could be controlled by OLTC through offline OPF [38]. The authors in [39] have compared a real network case study with no OLTC, five tap position on OLTC and nine tap position on OLTC. The results show that HC could be increased more than $50 \%$ in $16 \%$ scenarios and more than $100 \%$ in about $3 \%$. Moreover, not significant difference between 5 and 9 tap position had been reported in this paper, meaning that the OLTC HC impact is neighter depends on the size of network, nor the level of loading. In [40] different modern control schemes are discussed including Enhanced Transformer $\mathrm{Au}-$ tomatic Paralleling Package (TAPP) and super TAPP n+ relay, to reduce the circulating current between transformers and to estimate the RES output current respectively. In [41] state estimation approach is suggested for OLTC controlling.

DG injections cause voltage rise in the MV feeders, PFC could control the system's voltage by increasing the HC of the distribution grid. In [42]-[45], Static compensators (STATCOM), D-STATCOM, static VAR compensators (SVC), fixed capacitor banks and shunt capacitor banks have been investigated as generator compensators to regulate the voltage. Four different local control schemes are discussed in [46]-[48]. These schemes have been modified according to European technical standards, as listed in the following: LawA) control of tangent of $\phi$ according to the PCC voltage $(\tan \phi=f(u)) ; L a w B)$ control of reactive power according to the PCC voltage $(q=f(u)) ;$ LawC) control of tangent of $\phi$ according to the real power injected $(\tan \phi=f(p))$; $L a w D$ ) control of reactive power according to the real power injected $(q=f(p))$.

\section{B. Network Reconfiguration}

In [49] network reconfiguration is used for HC increasing by multi period optimal power flow. The proposed method in this paper, first solves the problem for periods with worst case scenarios, the resulting configuration is then assessed for remaining time periods to check if it comply with given constraints. The authors in [50], [51] purposed Genetic Algorithm (GA) based network reconfiguration to maximize $\mathrm{HC}$ at selected nodes. In this paper objective function is built to penalize network configurations leading to overloads of distribution lines and over or under voltages at buses. For a given network configuration, the fitness function is obtained by considering both the maximum allowed power supplied by DG sources and the exploitation of the lines together with the bus voltage profiles. Uniform Voltage Distribution Algorithm (UVDA) based constructive reconfiguration is used as heuristic in [52], [53]. Objective of the problem is to reconfigure the network and DG sizing to maximize network power loss reduction and HC. Particle Swarm Optimization (PSO) technique is used to find the best solution of the proposed multi-objective problem.

\section{RES Curtailment}

Active power curtailment has been used in some research studies and also finding its ways into national regulatory framework. RES production curtailment includes decreasing the output power of specific resources which HC would exceed the limitations [11]. One of the other big advantage of RES curtailment is to prevent inverters disconnection due to overvoltage tripping. The authors in [54] have compared two methods of active power limitation: fixed percentage of the nominal power and VoltWatt control where the active power depends on voltage. The results show the fixed curtailment has better performance compare to that VoltWatt control. In [55], optimal setting of DG curtailment based on multi-period OPF has been investigated for economic benefits. 


\section{THE PROPOSED APPROACH}

The novelty of the method proposed in this paper consists in the definition of a model easy to manage and that can be applied to the generality of network structures. This model is used in order to perform a set of PF computations aimed to evaluate the HC with respect to Steady State Voltage Variations (SSV), Rapid Voltage Change (RVC) and thermal limits of transformers and lines.

\section{A. Modeling of Distribution Grid}

1) Nodal Hosting Capacity: As already mentioned, HC is impacted by the topology of the grid, by grid parameters and also by power profiles of loads and generators; moreover, its evaluation requires a complete distribution grid model which results in a quite heavy data set to be properly managed. Practically speaking, DSOs could not have easy access to all the data required, thus a novel approach is proposed for the distribution grid modeling, namely Bricks approach.

Actually, the standard structure of distribution grids provides a main feeder departing from MV busbars in PS, and many branches connected to the main line typically named collaterals. A mathematical model has been developed in our work in order to represent the grid network with a conventional approach, so to evaluate the HC in a shorter time and in a practical way. The new method is based on the assumption that HC on one feeder is marginally affected by the behavior of other feeders. Moreover, in order to limit the computational effort of the study, the grid is modeled in a simplified way, i.e. is modeled as an aggregation of "bricks", each one representing a portion of the grid which can be added, removed and replaced stochastically to evaluate all the possible configurations of the grid structure. In addition, only the critical nodes of the grid (i.e. the busses actually representative of the behavior of the whole network) are assessed by the Bricks approach. Table 1 represents the grid model adopted in the Bricks approach [56].

2) Multi-Generator Hosting Capacity: In real life, by increasing the number of renewable energy integration at the same time many DG are connecting to the grid which affects other DGs and the grid [14]. The procedure developed in this research takes into account that DGs could be connected to the grid through different plants of different size and connected to various nodes. To evaluate if the distribution grid can host this capacity or if its installation will compromise the performances of the grid, a stochastic approach has been adopted, in particular Monte Carlo

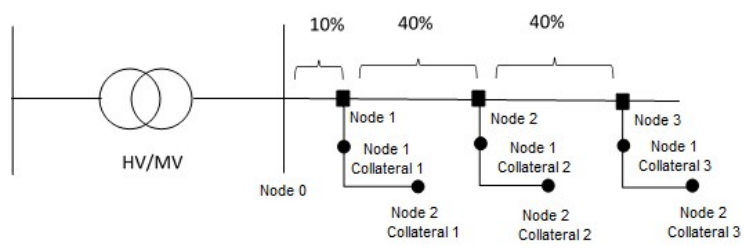

Fig. 3: Long feeder with three long collateral and its define nodes. simulation is exploited in order to properly consider all the variables.

Once Monte Carlo scenarios are created, the hourly PF computation is carried out considering defined technical constraints. By performing PF computation, system power losses, maximum voltage and maximum current of the grid is calculated. The Monte Carlo procedure is based on an iterative behavior and equation 1 and 2 represents the convergence criterion which is used in this study. $\mu_{\text {Loss }}$ and $\sigma_{\text {Loss }}$ are the losses mean value, and the losses standard deviation respectively. The variation of these two value should be placed lower than $\epsilon$.

$$
\begin{aligned}
& \left|\frac{\mu_{\text {Loss }}(i)-\mu_{\text {Loss }}(i-1)}{\mu_{\text {Loss }}(i-1)}\right|<\epsilon_{\mu} . \\
& \left|\frac{\sigma_{\text {Loss }}(i)-\sigma_{\text {Loss }}(i-1)}{\sigma_{\text {Loss }}(i-1)}\right|<\epsilon_{\sigma} .
\end{aligned}
$$

When Monte Carlo simulation for a specific capacity stops, total number of scenarios and the number of scenario which violated each technical constraint can be assessed. Hence, Hosting Capacity Violation Probability (HCVP) through equation 3 can be evaluated which the acceptable probability to violate the limit such as many stochastic approaches is considered 5\%.

$$
H C V P=\frac{\text { Total no. of scenario }}{\text { No. of scenario violate each constraint }} .
$$

\section{B. Validation of the Proposed Approach}

The formulated approach is applied to the MV network of Aosta city in north of Italy, departing from the "Ponte Pietra" PS that is located in the East of the city. The Aosta grid is supplied by two $25 \mathrm{kVA}$ transformers $132 / 15 \mathrm{kV}$, and is composed by 16 main feeders with an overall of 486 nodes; 9 feeders are connected to one transformer, and the other 7 are connected to the second one.

Fig. 4 represents the error of the Bricks approach in evaluating the HC. From the mentioned results, Bricks approach error did not go beyond $0.03 \mathrm{pu}$., which can be a proof of promising results. Moreover, computation time for Bricks approach was 5 minutes and 37 seconds, whereas for Real-Grid approach it was 92 hours and 43 minutes and 86 seconds.

In addition, Fig. 5 shows the HCVP for this grid according to defined technical constraints. From this picture, it is obvious thermal limits its a dominant constraint in this grid and the total $\mathrm{HC}$ is less than $10 \mathrm{MW}$.

\section{Conclusion}

Increasing penetration of distributed energy resources in distribution network needs active network management as it could cause system voltage violations and overloading. Hence, nowadays evaluating the maximum hosted generation by distribution grid (Hosting Capacity) is vital for distribution system operators. This paper reviewed the 
TABLE 1: Bricks Approach Components.

\begin{tabular}{|c|c|}
\hline Components & Remarks \\
\hline Feeders & $\begin{array}{l}\text { Feeders are categorized according to their impedance characteristic into three groups: Short Feeder, Medium Feeder and Long Feeder. } \\
\text { The feeders characteristic mean value in each category is considered as the main characteristic of the Bricks approach feeders. }\end{array}$ \\
\hline Collaterals & Collaterals are divided into two groups: Short Collateral and Long Collateral. Short feeders can only have a short collateral. \\
\hline Nodes & $\begin{array}{c}\text { Basically, the HC is higher at the beginning of the feeder close to the primary substation, whereas it decreases to the } \\
\text { end and collaterals. Therefore, three critical nodes in each feeder, at the } 10 \%, 50 \% \text { and } 90 \% \text { of the total amount of feeders impedance, } \\
\text { and two significant nodes in each collateral, at its middle and at its end are considered. } \\
\text { Figure } 3 \text { shows the defined nodes. }\end{array}$ \\
\hline Loads & Loads are divided into three groups: the yearly minimum value, the mean value and the peak value with power factor of 0.9 . \\
\hline Generators & $\begin{array}{l}\text { A generator is added to each defined-node, then the injected power to the grid is changed in the simulation to evaluate the HC. } \\
\text { Thanks to the proposed approach, in order to evaluate a "general" network topology a number of grid configurations equal to } 10449 \text { (ex. } \\
\text { For long feeder and long collateral at its end, } 3 \text { combinations of load for each } 5 \text { nodes and } 5 \text { combinations of placing DG } \\
\text { which represents } 1215 \text { combinations) needs to be assessed through PF computations. Actually, MV distribution grids could have } \\
\text { hundreds of nodes, in order to evaluate their HC in different working conditions (e.g. sampling a calendar } \\
\text { year hourly) a significant higher number of PF computations would be required. }\end{array}$ \\
\hline $\begin{array}{l}\text { Load Flow } \\
\text { Calculation }\end{array}$ & $\begin{array}{c}\text { HC evaluation is based on bisectional method by root-finding behavior, the load flow iteration will continue until its } \\
\text { convergence. }\end{array}$ \\
\hline
\end{tabular}

different hosting capacity analysis and the different ways to increase it. At the end, a new effective computative method to evaluate the hosting capacity in case of grid parameter uncertainties and multi-generator connection was proposed.

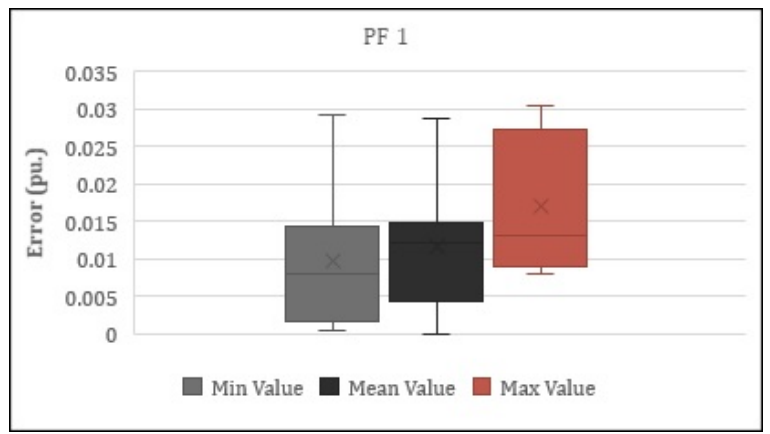

Fig. 4: Errors in HC evaluation adopting the Bricks model.
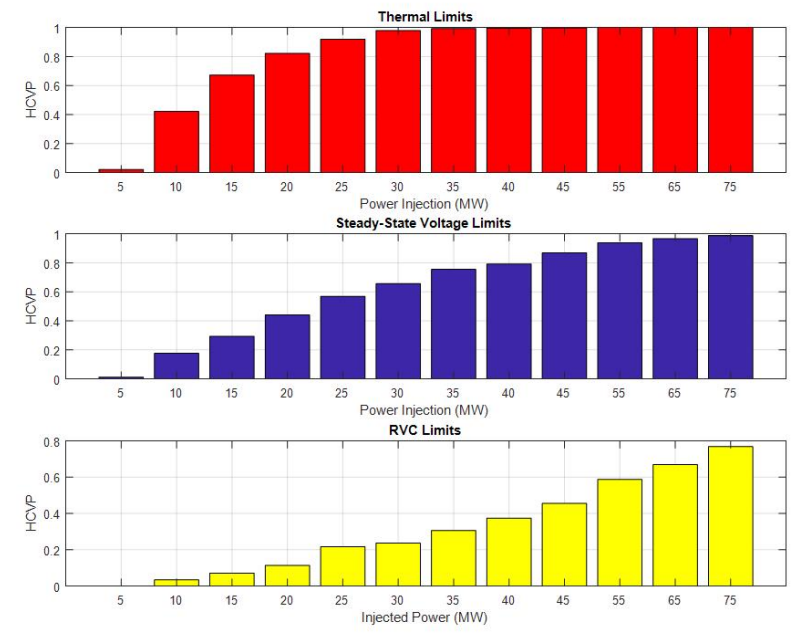

Fig. 5: HCVP of Aosta grid for each technical constraints.

\section{REFERENCES}

[1] M. Bollen and M. Häger, Power quality: interactions between distributed energy resources, the grid, and other customers, Leonardo Energy, 2005.

[2] R. Walling, R. Saint, R. C. Dugan, J. Burke, and L. A. Kojovic, Summary of distributed resources impact on power delivery systems, IEEE Transactions on power delivery, vol. 23, pp. 1636-1644, 2008.

[3] J. P. Lopes, N. Hatziargyriou, J. Mutale, P. Djapic, and N. Jenkins, Integrating distributed generation into electric power systems: A review of drivers, challenges and opportunities, Electric power systems research, vol. 77, pp. 1189-1203, 2007.

[4] M. Delfanti, D. Falabretti, M. Merlo, G. Monfredini, and V. Olivieri, Dispersed generation in mv networks: performance of anti-islanding protections, in Harmonics and Quality of Power (ICHQP), 2010 14th International Conference on, 2010, pp. 1-6.

[5] C. Mozina, Impact of green power distributed generation, IEEE Industry Applications Magazine, vol. 16, $\mathrm{n}^{\circ}$ 4, pp. 55-62, Julho 2010.

[6] M. Bollen, Y. Yang, and F. Hassan, Integration of distributed generation in the power system-a power quality approach, in Harmonics and Quality of Power, 2008. ICHQP 2008. 13th International Conference on, 2008, pp. 1-8.

[7] N. Jenkins, Embedded generation, Power Engineering Journal, vol. 9, pp. 145-150, 1995.

[8] [AEEG] 2008, Integrated Text of the technical and economic conditions for connection to electricity grids with the obligation to connect third of the production facilities of electricity, [Online]. Available: http://www.autorita.energia.it/it/docs/08/099-08arg.htm

[9] G. Celli, E. Ghiani, S. Mocci, and F. Pilo, A multiobjective evolutionary algorithm for the sizing and siting of distributed generation, IEEE Transactions on power systems 20.2 (2005): 750-757.

[10] P. Prakash, D. K. Khatod, Optimal sizing and siting techniques for distributed generation in distribution systems: A review, Renewable and Sustainable Energy Reviews 57 (2016): 111-130.

[11] N. Etherden and M. H. Bollen, Increasing the hosting capacity of distribution networks by curtailment of renewable energy resources, in PowerTech, 2011 IEEE Trondheim, 2011, pp. 1-7.

[12] M. Delfanti, M. S. Pasquadibisceglie, M. Pozzi, M. Gallanti, and R. Vailati, Limits to dispersed generation on Italian MV networks, in Electricity Distribution-Part 1, 2009. CIRED 2009. 20th International Conference and Exhibition on, 2009, pp. 1-4.

[13] J. Deuse, S. Grenard, K. Karoui, O. Samuelsson, L. Gertmar, P. Karlsson, et al., Interactions of dispersed energy resources with power system in normal and emergency conditions, in CIGRE 2006 Conference, 2006.

[14] Ding, Fei, and Barry Mather. On Distributed PV Hosting Capacity Estimation, Sensitivity Study, and Improvement, IEEE Transactions on Sustainable Energy 8.3 (2017): 1010-1020.

[15] C. Schwaegerl, et al, Voltage control in distribution systems as a limitation of the hosting capacity for distributed energy resources, Int. Conf. on Electric Distribution Systems (CIRED), June 2005. 
[16] J. Deuse, S. Grenard, M.H.J. Bollen, EU-DEEP integrated proect Technical implications of the hosting-capacity of the sytem for DER, Int Journal of Distributed Energy Resources, Vol.4, No.1 (2008), pp.17-34.

[17] G. Bourgain, J. Deuse, S. Galant, A. Vafeas, G. Bercq, C. Alvarez, Integrating Distributed Energy Resources in today's electrical energy system, June 2009, ExpandDER.

[18] O. Lennerhag, Using measurements to increase the accuracy of hosting capacity calculations, CIRED-Open Access Proceedings Journal 2017.1 (2017): 2041-2044.

[19] N. Etherden, M. Bollen, S. Ackeby, O. Lennerhag, The transparent hosting capacity approach overview, applications and developments, International Conference and Exhibition on Electricity Distribution: June 2015

[20] D. Bertini, D. Falabretti, M. Merlo, D. Moneta, et al. Hosting capacity of Italian LV distribution networks, 21st International Conference on Electricity Distribution. 2011.

[21] F. AlAlamat, Increasing the hosting capacity of radial distribution grids in Jordan, (2015).

[22] N. Etherden, Increasing the hosting capacity of distributed energy resources using storage and communication, Diss. Luleå tekniska universitet, 2014.

[23] M. Alturki, Hosting Capacity Calculations in Power Systems, 2014.

[24] A. Kulmala, S. Repo, J. Pylvänäinen, Generation curtailment as a means to increase the wind power hosting capacity of a real regional distribution network, CIRED-Open Access Proceedings Journal 2017.1 (2017): 1782-1786.

[25] M. Delfanti, M. Merlo, G. Monfredini, V. Olivieri, M. Pozzi, and A. Silvestri, Hosting dispersed generation on Italian MV networks: Towards smart grids, in Harmonics and Quality of Power (ICHQP), 2010 14th International Conference on, 2010, pp. 1-6.

[26] M. Delfanti, M. Merlo, M. Pozzi, V. Olivieri, and M. Gallanti, Power flows in the Italian distribution electric system with dispersed generation, in Electricity Distribution-Part 1, 2009. CIRED 2009. 20th International Conference and Exhibition on, 2009, pp. 1-5.

[27] D. Menniti, M. Merlo, N. Scordino, N. Sorrentino, F. Zanellini, A DSOoriented mathematical model for dispersed generation management on MV networks. Power and Energy Society General Meeting, 2012 IEEE. IEEE, 2012.

[28] M. Merlo, N. Scordino, F. Zanellini, Optimal power flow approach to manage dispersed generation rise and passive load energy needs over a distribution grid, International Review of Electrical Engineering (IREE) 8.5 (2013): 1482-1494.

[29] L.J. Thomas, A. Burchill, D.J. Rogers, M. Guest, N. Jenkins, Assessing Distribution Network Hosting Capacity With The Addition Of Soft Open Points, 5th IET International Conference on Renewable Power Generation (RPG) 2016 (2016): n. pag. Web. 24 Apr. 2017.

[30] L. D. Campello, P. M. Duarte, P. F. Ribeiro, T. E. de Oliveira, Hosting capacity of a university electrical grid considering the inclusion of wind-turbines for different background distortions, Harmonics and Quality of Power (ICHQP), 2016 17th International Conference on. IEEE, 2016.

[31] H. Iyer, S. Ray, R. Ramakumar, Assessment of distributed generation based on voltage profile improvement and line loss reduction, 2005/2006 IEEE/PES Transmission and Distribution Conference and Exhibition, 2006.

[32] A. Rabiee, S.M. Mohseni-Bonab, Maximizing hosting capacity of renewable energy sources in distribution networks: A multi-objective and scenario-based approach, Energy 120 (2017): 417-430.

[33] J. Le Baut, P. Zehetbauer, S. Kadam, B. Bletterie, N. Hatziargyriou, J. Smith, M. Rylander, Probabilistic evaluation of the hosting capacity in distribution networks, PES Innovative Smart Grid Technologies Conference Europe (ISGT-Europe), 2016 IEEE. IEEE, 2016.

[34] E. Zio, M. Delfanti, L. Giorgi, V. Olivieri, G. Sansavini, Monte Carlo simulation-based probabilistic assessment of DG penetration in medium voltage distribution networks, International Journal of Electrical Power and Energy Systems 64 (2015): 852-860.

[35] T. Walla, Hosting capacity for photovoltaics in Swedish distribution grids, 2012.

[36] M. Kolenc, P. Igor Papič, B. Boštjan, Assessment of maximum distributed generation penetration levels in low voltage networks using a probabilistic approach, International Journal of Electrical Power and Energy Systems 64 (2015): 505-515.
[37] A. Navarro-Espinosa, L. F. Ochoa, Probabilistic impact assessment of low carbon technologies in $\mathrm{LV}$ distribution systems, IEEE Transactions on Power Systems 31.3 (2016): 2192-2203.

[38] C. Gao , M. A. Redfern, A review of voltage control techniques of networks with distributed generations using OnLoad Tap Changer transformers, 45th International Universities Power Engineering Conference (UPEC) (2010), 1-6.

[39] K. Rauma, F. Cadoux, N. Hadj-Saïd, A. Dufournet, C. Baudot, G. Roupioz, Assessment of the MVILV on-load tap changer technology as a way to increase $L V$ hosting capacity for photovoltaic power generators, (2016): 44-4.

[40] C. R. Sarimuthu, V. K. Ramachandaramurthy, K. Agileswari, and H. Mokhlis, A review on voltage control methods using on-load tap changer transformers for networks with renewable energy sources, Renewable and Sustainable Energy Reviews, vol. 62, pp. 1154-1161, 2016.

[41] S. N. Salih and P. Chen, On coordinated control of OLTC and reactive power compensation for voltage regulation in distribution systems with wind power, IEEE Transactions on Power Systems, vol. 31, pp. 40264035, 2016.

[42] M. Elnashar, M. Kazerani, R. El Shatshat, M. M. A. Salama, Comparative evaluation of reactive power compensation methods for a stand-alone wind energy conversion system, IEEE Power Electronics Specialists Conference (2008), 4539- 4544

[43] M. Aggarwal, S. K. Gupta, M. Madhusudan, G. Kasal, DSTATCOM Control in Low Voltage Distribution System with Distributed Generation, 3rd Int. Conf. on Emerging Trends in Engineering and Technology (ICETET) (2010), 426-429.

[44] D. Caples, S. Boljevic, M. F. Conlon, Impact of distributed generation on voltage profile in $38 \mathrm{kV}$ distribution system, 8th International Conference on the European Energy Market (EEM) (2011), 532-536.

[45] D. Kumar, S. R. Samantaray, Implementation of multi-objective seekeroptimization-algorithm for optimal planning of primary distribution systems including DSTATCOM, International Journal of Electrical Power and Energy Systems 77 (2016), 439-449.

[46] M. Delfanti, L. Frosio, G. Monfredini, M. Merlo, C. Rosati, D. Rosati, et al., Technical Strategies for Voltage Power Regulation in LV Distribution Networks, Distributed Generation and Alternative Energy, p. 7, 2015.

[47] M. Delfanti, M. Merlo, and G. Monfredini, Voltage Control on LV Distribution Network: Local Regulation Strategies for DG Exploitation, Research Journal of Applied Sciences, Engineering and Technology, vol. 7, pp. 4891-4905, 2014.

[48] A. Berizzi, C. Bovo, D. Falabretti, V. Ilea, M. Merlo, G. Monfredini, et al., Architecture and functionalities of a smart Distribution Management System, in Harmonics and Quality of Power (ICHQP), 2014 IEEE 16th International Conference on, 2014, pp. 439-443.

[49] F. Capitanescu, L. F. Ochoa, H. Margossian, N. D. Hatziargyriou, Assessing The Potential Of Network Reconfiguration To Improve Distributed Generation Hosting Capacity In Active Distribution Systems, IEEE Transactions on Power Systems 30.1 (2015): 346-356.

[50] V. Calderaro, A. Piccolo, and P. Siano. Maximizing DG Penetration in Distribution Networks By Means Of GA Based Reconfiguration, 2005 International Conference on Future Power Systems (2005): n. pag. Web. 24 Apr. 2017.

[51] P. C. Ramaswamy, P. Vingerhoets, and G. Deconinck, Reconfiguring Distribution Grids For More Integration Of Distributed Generation, 22nd International Conference and Exhibition on Electricity Distribution (CIRED 2013) (2013): n. pag. Web. 24 Apr. 2017.

[52] A. Bayat, A. Bagheri, and R. Noroozian, Optimal Siting And Sizing Of Distributed Generation Accompanied By Reconfiguration Of Distribution Networks For Maximum Loss Reduction By Using A New UVDABased Heuristic Method, International Journal of Electrical Power and Energy Systems 77 (2016): 360-371.

[53] A. Bayat, Uniform voltage distribution based constructive algorithm for optimal reconfiguration of electric distribution networks, Electric Power Systems Research 104 (2013): 146-155.

[54] B. Bletterie, S. Kadam, J. Le Baut, Increased hosting capacity by means of active power curtailment, (2016): 194-4.

[55] W. Sun, G. P. Harrison, Influence of generator curtailment priority on network hosting capacity, (2013): 1453-1453.

[56] S. M. Mirbagheri, D. Falabretti, M. Merlo, Hosting Capacity Evaluation in Networks with Parameter Uncertainties, ICHQP, 2018 IEEE International Conference on Harmonics and Power Quality. 